Prepared for the U.S. Department of Energy under Contract DE-AC05-76RL01830

\title{
Preventing Absenteeism and Promoting Resilience Among Health Care Workers in Biological Emergencies
}

\section{AM Lesperance}

JS Miller

1 Department of Homeland Security Scholar, Harvard University

August 2009

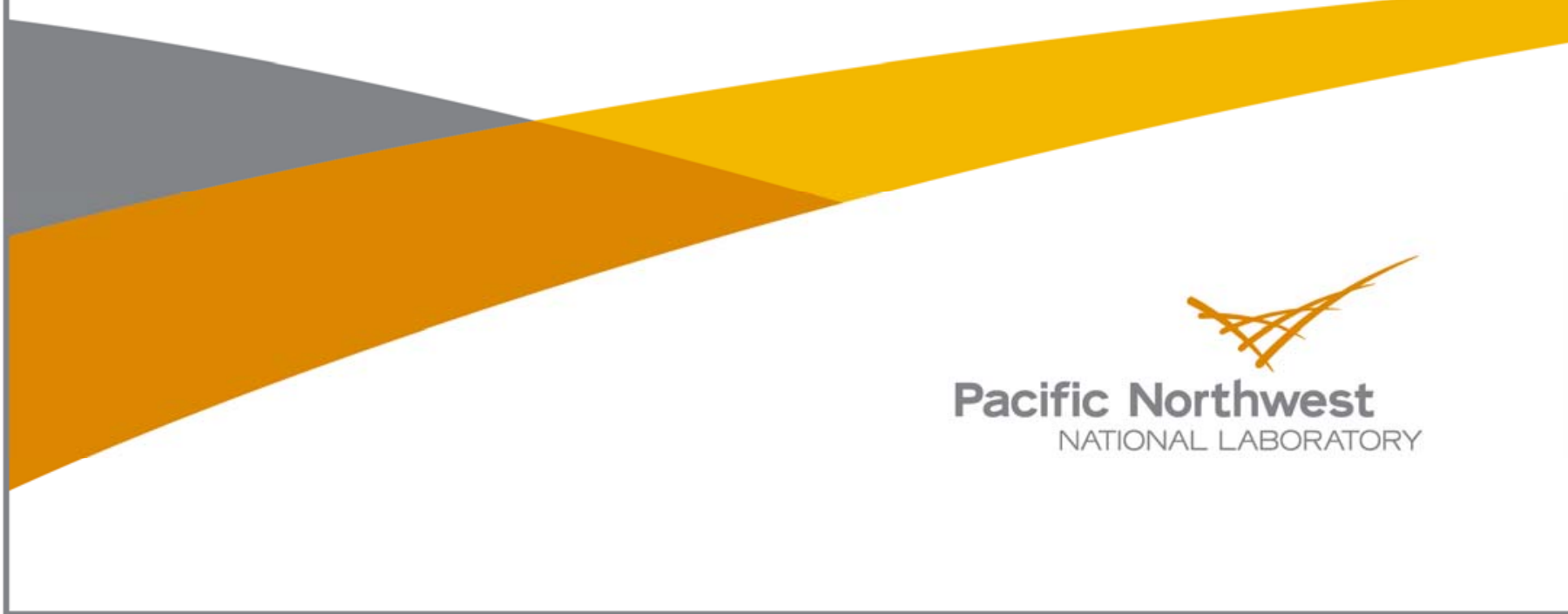




\title{
DISCLAIMER
}

This report was prepared as an account of work sponsored by an agency of the United States Government. Neither the United States Government nor any agency thereof, nor Battelle Memorial Institute, nor any of their employees, makes any warranty, express or implied, or assumes any legal liability or responsibility for the accuracy, completeness, or usefulness of any information, apparatus, product, or process disclosed, or represents that its use would not infringe privately owned rights. Reference herein to any specific commercial product, process, or service by trade name, trademark, manufacturer, or otherwise does not necessarily constitute or imply its endorsement, recommendation, or favoring by the United States Government or any agency thereof, or Battelle Memorial Institute. The views and opinions of authors expressed herein do not necessarily state or reflect those of the United States Government or any agency thereof.

\author{
PACIFIC NORTHWEST NATIONAL LABORATORY \\ operated by \\ BATTELLE \\ for the \\ UNITED STATES DEPARTMENT OF ENERGY \\ under Contract DE-ACO5-76RL01830
}

Printed in the United States of America

Available to DOE and DOE contractors from the

Office of Scientific and Technical Information,

P.O. Box 62, Oak Ridge, TN 37831-0062;

ph: (865) 576-8401

fax: (865) 5765728

email: reports@osti.gov

Available to the public from the National Technical Information Service,

U.S. Department of Commerce, 5285 Port Royal Rd., Springfield, VA 22161

ph: (800) 553-6847

fax: (703) 605-6900

email: orders@ntis.gov

online ordering: http://www.ntis.gov/help/ordermethods.aspx\#online 


\title{
Preventing Absenteeism and Promoting Resilience Among Health Care Workers in Biological Emergencies
}

\author{
AM Lesperance \\ JS Miller $^{1}$ \\ 1 Department of Homeland Security Scholar, Harvard University
}

August 2009

Prepared for

the U.S. Department of Energy

under Contract DE-AC05-76RL01830

Pacific Northwest National Laboratory

Richland, Washington 99352 



\section{Executive Summary}

Since the terrorist attacks of September 11, 2001, and the 2003 severe acute respiratory syndrome epidemic, homeland security and emergency response communities have increasingly focused on planning for disaster medical surge capacity - the capacity of the health care system to respond to a large influx of patients after a disaster. The ability to ensure adequate numbers of medical staff represents a crucial part of the medical response to any disaster. However, healthcare worker absenteeism during disasters, especially in the event of an attack of biological terrorism or an epidemic, such as pandemic influenza, is a serious concern.

Though a significant rate of absenteeism is often included as a baseline assumption in emergency planning, published reports on strategies to minimize absenteeism are comparatively few. This report documents interviews with managers and emergency response planners at hospitals and public health agencies and reviews existing survey data on healthcare worker absenteeism and studies of disasters to glean lessons about the needs of healthcare workers during those disasters. Based on this research, expected rates of absenteeism and individual determinants of absenteeism are presented along with recommendations of steps that hospitals, emergency medical services organizations, public health organizations, and government agencies can take to meet the needs of healthcare workers and minimize absenteeism during a biological event. 



\section{Acknowledgments}

This work was conducted in support of the Interagency Biological Restoration Demonstration, a collaborative regional program jointly funded by the U.S. Department of Defense-Defense Threat Reduction Agency and the U.S. Department of Homeland Security (DHS) designed to develop policies, methods, plans, and applied technologies to restore large urban areas, DoD installations, and critical infrastructure following the release of a biological event. The authors would also like to thank the DHS Science and Technology Directorate's University Programs Office for sponsoring James Miller's summer internship in 2008, which allowed him to conduct this research. In addition, the authors are indebted to all of our interviewees, who took the time to share their expertise and experience in this field. 



\section{Acronyms and Abbreviations}

AIDS

CDC

DHS

EMS

FEMA

HIV hum

OSHA

PPE

SARS acquired immune deficiency syndrome

Centers for Disease Control and Prevention

Department of Homeland Security

Emergency Medical Services

Federal Emergency Management Agency

an immunodeficiency virus

Occupational Safety and Health Administration

personal protective equipment

severe acute respiratory syndrome 



\section{Contents}

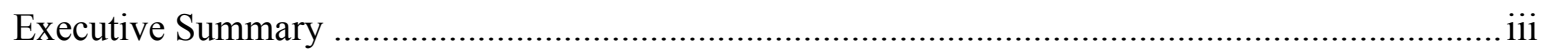

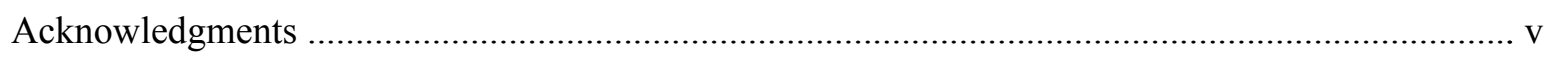

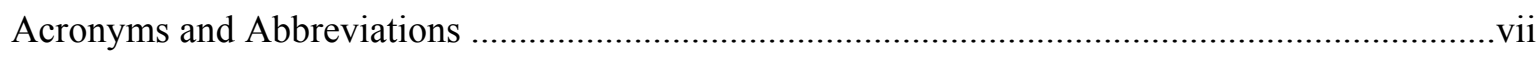

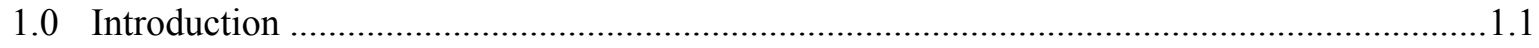

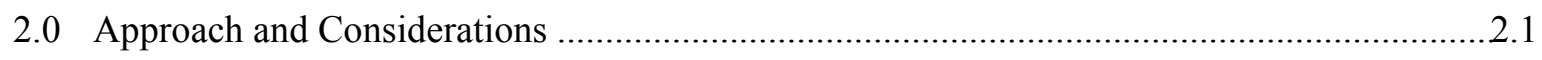

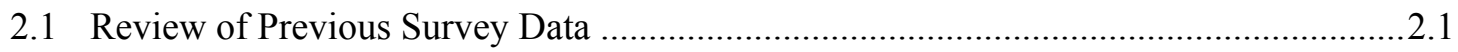

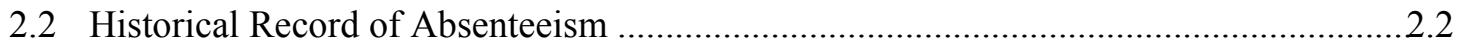

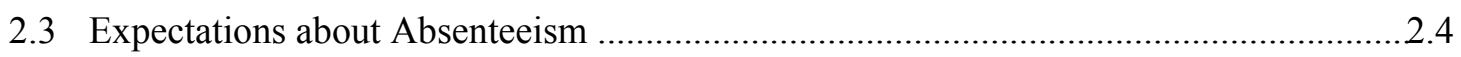

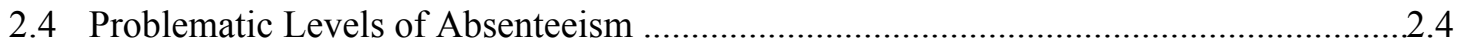

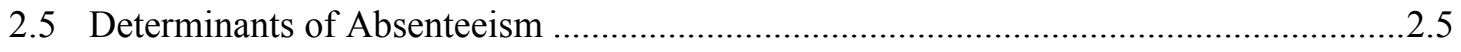

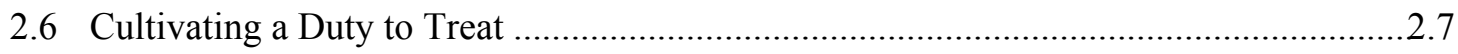

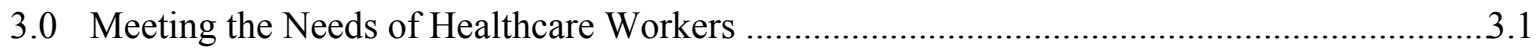

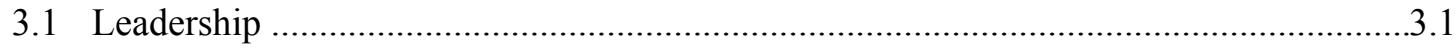

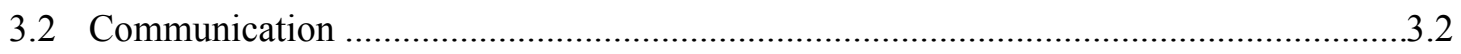

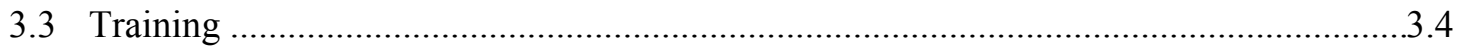

3.4 Personal Protection, Prophylaxis, and Security …....................................................

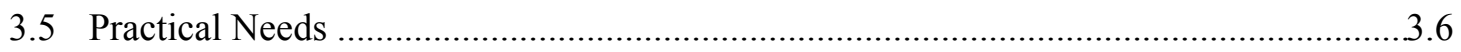

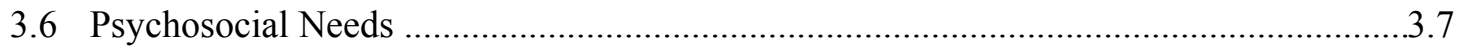

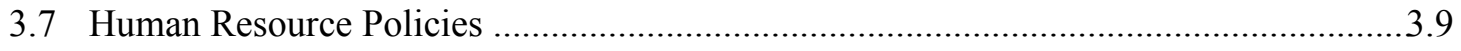

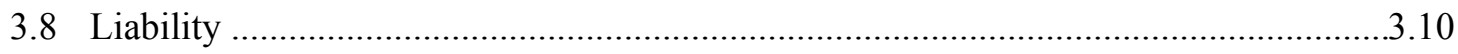

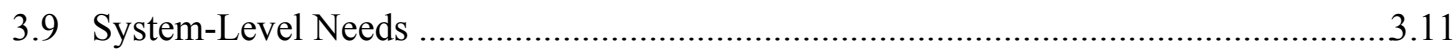

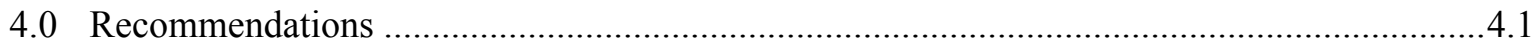

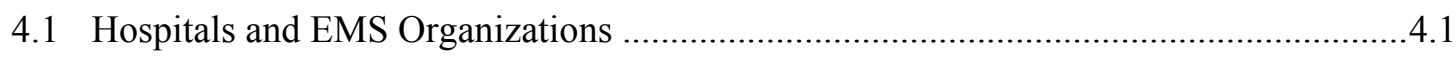

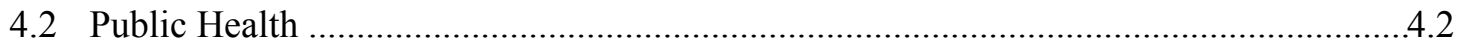

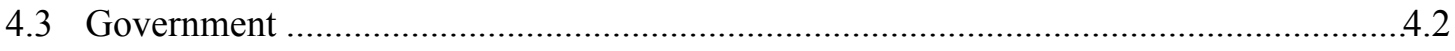

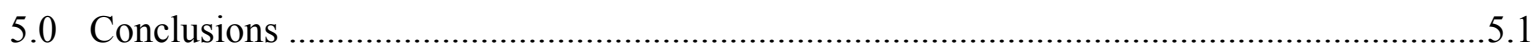

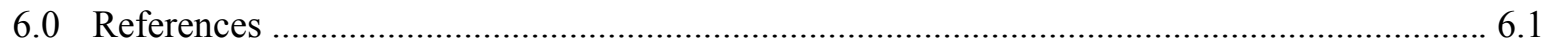

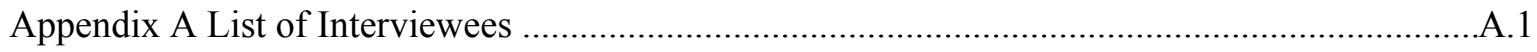

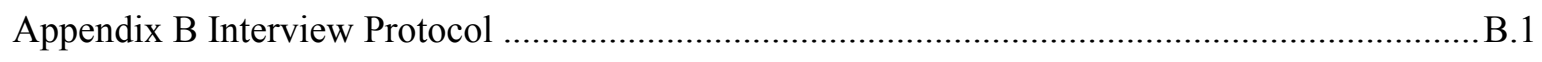





\subsection{Introduction}

Since the attacks of September 11, 2001 and the 2003 severe acute respiratory syndrome (SARS) epidemic, the homeland security and emergency response communities have increasingly focused on planning for disaster medical surge capacity - the capacity of the healthcare system to respond to a large influx of patients after a disaster. Concerns about avian influenza have only underscored the need for such surge planning. In the face of a frightening and potentially fatal biological threat, some healthcare workers might decide to avoid working out of fear for their own safety and that of their families; absenteeism among staff, combined with a rapid influx of patients, could overwhelm the ability of a health system to provide adequate care.

Comparatively little research has focused on preventing absenteeism by meeting the needs of healthcare workers, especially in the unique context of a biological event, such as an epidemic or biological agent attack. Though the use of volunteers or federal response capabilities, such as Disaster Medical Assistance Teams, may be necessary, the ideal solution to disaster staffing is to retain as many current staff as possible. This report examines the rates of healthcare worker absenteeism that might be expected during a biological event, as well as measures that hospitals, public health departments, and government agencies can take to meet the needs of healthcare workers and minimize absenteeism. 



\subsection{Approach and Considerations}

Between June 25, and August 7, 2008, 28 individuals were interviewed. They represented a wide range of job roles and expertise, including civilian and military physicians involved in emergency response planning, nurse managers, Emergency Medical Services (EMS) administrators, local public health officials, state public health officials, and regional U.S. Department of Health and Human Services officials. Their job responsibilities ranged from the strategic to the tactical, and a number of the interviewees had firsthand experience in responding to epidemics and other disasters, including SARS, the 2001 Capitol Hill anthrax attacks, and Hurricane Katrina. The interviews were semi-structured and non-remunerated. Because interviewees were guaranteed the anonymity of their responses, quotations and information obtained from them are presented in this report without attribution. Appendix A contains the names of those who consented to be listed in the report. Appendix B contains a generic version of the interview protocol (it was customized for each interviewee).

In addition to these interviews, a literature search identified survey data regarding healthcare workers' willingness to respond to biological events, as well as the needs and concerns they would face in an epidemic. Responses and needs were also gathered from the PubMed citation database, government websites, and newspaper articles, which provided historical examples of epidemics and other disasters.

For the purpose of this report, the term "healthcare worker" is defined to include both clinical and nonclinical hospital staff, EMS personnel, and public health workers. While some of the literature focuses only on physicians, all healthcare workers are important in implementing a successful response to an epidemic and so are considered in this report.

The information in this article may be useful to leaders in hospitals, EMS units, and public health departments in preparing their organizations and workforces for future epidemics. However, only by addressing these needs at the public policy level will the nation's healthcare system be made resilient enough to withstand the impact of a biological event.

\subsection{Review of Previous Survey Data}

In the last five years, a number of authors have surveyed healthcare workers to assess their willingness to treat patients during a biological terrorism attack, an influenza pandemic, or other biological event. Most surveys have found fairly similar results, though, not surprisingly, the specific biological agent has an impact on responses. Qureshi et al. (2005) surveyed New York healthcare workers about their willingness to report to work during a chemical event, a smallpox epidemic, a radiation event, and a SARS epidemic - 67.7\% said they would be willing to report to work for a chemical event, compared with $61.1 \%$ for smallpox, $57.3 \%$ for radiation, and $48.4 \%$ for SARS.

A smaller survey of Washington, D.C. healthcare workers found similar results - $70 \%$ of employees said they would come to work if chemically contaminated patients were in the hospital, compared with $66 \%$ for radiologically contaminated patients, and $62 \%$ for biologically contaminated patients (Hanfling 2005). This survey did not specify the biological agent making comparison somewhat difficult. Masterson et al. (2008) conducted a similar survey of emergency department personnel and found a much higher willingness to report to work during a radiation event $(85.3 \%)$ but a fairly similar result for a biological event (54\%). Balicer et al. (2006) surveyed local public health department employees in 
Maryland and found that $53.8 \%$ of employees said they were likely to report to work during a flu pandemic. Thus, these survey data predict an extremely high rate of healthcare worker absenteeism-in the range of $40 \%$ to $50 \%$.

Alexander and Wynia (2003) found that the phrasing of the question substantially impacted responses about willingness to treat patients. They found that $80 \%$ of surveyed physicians were willing to continue to care for patients in the event of an outbreak of an unknown but potentially deadly illness, whereas only $40 \%$ said they were willing to put themselves at risk of contracting a deadly illness to save the lives of others, and only $33 \%$ would care for infected smallpox patients if unvaccinated. Even if assured postexposure vaccination, only $72 \%$ of physicians were willing to care for smallpox patients (Alexander et al. 2006). Meanwhile, only 55\% of physicians agreed that they had an obligation to care for patients in epidemics even if doing so endangered their own health (Alexander and Wynia 2003).

Though this study did not focus on comparing data cross-culturally, these estimates appear fairly similar to those in other countries. In Taiwan, for example, $56.9 \%$ of nurses in one survey expressed willingness to care for patients with avian flu. In Germany, $28 \%$ of healthcare providers agreed or strongly agreed that "it is professionally acceptable for [health care providers] to abandon their workplace during a pandemic in order to protect themselves and their families" (Ehrenstein et al. 2006).

Qureshi et al. (2005) also explored the issues that healthcare staff report as barriers to working during disasters. The key barriers noted in that survey were identical to those identified in the interviews discussed in this report - fear and concern for family, fear and concern for self, transportation issues, personal health issues, childcare, elder care, and pet care (Qureshi et al. 2005). These barriers, as well as steps that healthcare institutions can take in overcoming them, are discussed later in this report.

\subsection{Historical Record of Absenteeism}

Because of the potential limitations of survey data in accurately predicting behavior during disasters, the study also examined rates of absenteeism in past epidemics. This issue received previous attention during the early years of the acquired immune deficiency syndrome (AIDS) epidemic, as researchers explored whether physicians' responses to human immunodeficiency virus (HIV) were similar to those in past epidemics. Zuger and Miles (1987) have argued that, in a review of the history, "no consistent professional tradition emerged."

However, this assessment may be overly bleak. Since the 1850 s, examples of absenteeism among physicians have been quite scarce (Arras 1988). In 1847, the American Medical Association formally codified a "duty to treat" in its Code of Ethics, "When pestilence prevails, it is [physicians'] duty to face the danger, and to continue their labors for the alleviation of suffering, even at the jeopardy of their own lives" (Huber and Wynia 2004). In the ensuing decades, it seems that physicians were indeed willing to jeopardize their own lives. In one particularly dramatic example, during the 1878 yellow fever epidemic in Memphis, 45 of the 111 physicians in the city perished (Arras 1988). Among these physicians, the duty to treat seems to have endured even amidst an overwhelming casualty rate.

However, a number of authors have suggested that this commitment to a duty to treat crumbled in the face of the HIV epidemic. Bayer (1988) catalogued a number of instances of surgeons publicly declaring their refusal to treat HIV-positive patients. Cohen (1992) described private refusals by surgeons, dentists, and abortion providers. In the current study, one of the interviewees, an infectious disease physician who 
had treated HIV patients in the late 1980s, described several situations in which healthcare workers refused to treat HIV patients - the workers who delivered food refused to enter the rooms of the HIV patients and surgeons refused to operate or decided that the operation was no longer necessary once they discovered that the patient was HIV positive. Though the HIV epidemic did not lead to absenteeism per se (in that employees continued showing up to work), it does appear to have precipitated refusals to treat.

The behavior of healthcare workers during the early years of the HIV epidemic raises the question of whether healthcare workers may now feel less of an obligation to treat patients who might pose a risk their health, or whether the response to HIV was an anomaly caused by the lack of knowledge about, and deep stigmatization of, this disease. Though both the survey data and the responses to HIV suggest that many healthcare workers may not feel a strong duty to treat patients with an infectious disease, the experience during the SARS epidemic contradicts this assessment. SARS posed a much greater risk to healthcare workers than did HIV and was similarly somewhat unknown, and yet, especially in Canada, rates of absenteeism were incredibly low. Some hospitals in Vietnam and Hong Kong reported significant absenteeism, though these may have been isolated instances (Altman 2003).

In Toronto, however, healthcare worker absenteeism does not seem to have been a problem. Anecdotal reports detailed physicians refusing to consult with suspected SARS patients (Rambaldini et al. 2005) and some reports told of nurses and physicians refusing to care for SARS patients or resisting being assigned to a SARS ward (Maunder et al. 2003, Campbell 2006). However, there is little evidence that any significant number of healthcare workers failed to report to work. In the current study, one interviewee who was involved with the SARS response reported virtually no absenteeism among clinical or nonclinical staff. In fact, he claimed that the greater problem was convincing healthcare workers to stay home if they had any SARS symptoms - many healthcare workers with mild symptoms reported to the hospital anyway. Other interviewees, as well published articles, similarly report very low rates of absenteeism (Booth and Stewart 2005, Campbell 2006, Maunder et al. 2003).

Though some interviewees questioned whether healthcare workers would respond differently to an act of terrorism, these fears do not seem to have materialized during the 2001 Capitol Hill anthrax attacks. No published report of healthcare worker absenteeism during the treatment of patients exposed to anthrax was found in the literature review. In the current study, one interviewee who was involved in the response to this event reported no problems with absenteeism in military or civilian hospitals. ${ }^{1}$

The discordance between the survey data on absenteeism and these experiences is rather striking. As was previously noted, approximately $40 \%$ of healthcare workers said that they would not attend work if biologically contaminated patients were in the hospital (Hanfling 2005, Masterson et al. 2008), and over $50 \%$ said they would not report to work during a SARS epidemic (Qureshi et al. 2004). Granted, the survey participants were American healthcare workers, whereas the healthcare workers responding to SARS were Canadian. However, it seems unlikely that Canadian and American healthcare workers are dissimilar enough to explain this difference between the survey responses and actual behavior.

\footnotetext{
${ }^{1}$ The military involvement in the response to the anthrax attacks may have played a role in decreasing absenteeism, since military hospitals have substantial power to compel their uniformed employees to work. The attention that the military pays to unit cohesion and leadership may also have prevented absenteeism.
} 


\subsection{Expectations about Absenteeism}

The inconsistency between surveys and past experience creates a conundrum for leaders in hospitals, EMS, and public health organizations who are attempting to plan for epidemics. Indeed, this uncertainty was echoed strongly in the study interviews. The interviewees fell into two main groups; one group felt that the survey data were approximately correct and said that they were planning for $25 \%$ to $30 \%$ of their staff refusing to work. The other group felt that very few employees would refuse to work, while they anticipated staffing shortages in a pandemic flu scenario because $30 \%$ to $40 \%$ of staff could be ill themselves, they did not anticipate staffing shortages caused by refusal to work. Some cited the SARS epidemic as justification for their expectations. As one interviewee put it, "I don't think healthcare workers will be absent (because of fear) for pandemic flu, because it didn't happen during SARS." Though a few interviewees took the middle ground, saying that they were planning for $5 \%$ to $10 \%$ of employees refusing to work, for the most part, the interviewees were split between those expecting very significant absenteeism and those expecting very little absenteeism (except that caused by illness).

A number of possible explanations for the discrepancy between survey data and actual experience in the SARS epidemic merit further exploration. One explanation centers on the fact that a comparatively small number of patients contracted SARS. Only a fraction of Toronto healthcare workers were actually caring for SARS patients; thus it is possible that, if every healthcare worker had been needed to care for SARS patients, $50 \%$ would have absented themselves from work. Therefore, absenteeism might have been more easily observed during a catastrophic event with wide-area impacts. However, because of the small number of patients, only those healthcare workers who were willing to care for SARS patients provided direct care. The weakness of this explanation lays in the vague nature of SARS symptoms. Given the initial lack of knowledge surrounding SARS and the difficulty in conclusively diagnosing the disease, all healthcare workers ran some risk of contracting SARS, regardless of whether they were actually caring for SARS patients. The low levels of absenteeism observed at hospitals that took care of SARS patients suggest that healthcare workers were more willing to accept the very real risk of contracting SARS than the survey data imply. It may be that healthcare workers have insufficient information about hypothetical events and therefore tend to overestimate the risks posed to them in these events; however, during a real event, they arrive at a more accurate assessment of risk.

\subsection{Problematic Levels of Absenteeism}

The current set of interviews also explored the levels of absenteeism that would impact the quality of healthcare provided by a system. Hospital administrators indicated they have the option of using longer shift schedules to fill in for absent staff, though most did not quantify the rate of absenteeism that would render this approach insufficient. They emphasized that hospital operations depend greatly on having a full complement of staff on duty, because hospitals are very interdependent units. One interviewee gave an example of a scenario in which a third of the radiology technicians were absent. Even if all the other staff in the hospital were present, the absence of the radiology technicians would significantly impact patient flow.

A number of interviewees also mentioned the extent to which hospitals rely on nonclinical staff. Employees, such as the unit secretaries, are essential for keeping the clinical unit running smoothly; although absenteeism among nonclinical staff is perhaps less problematic than absenteeism among clinical staff, it can nonetheless interfere with normal operations. 
EMS administrators indicated that, by changing shift schedules and shifting personnel, they could handle approximately a $20 \%$ rate of absenteeism before they had to reduce services. EMS organizations appear to be somewhat more resilient to the effects of absenteeism than hospitals, because they are less interdependent.

\subsection{Determinants of Absenteeism}

The interviews also sought to draw out the determinants of absenteeism, because most of the survey data do not address this issue. Questions addressed both the characteristics of biological events that might make healthcare workers more or less likely to be absent, as well as potential rates of absenteeism among different groups of staff. Though the reports were anecdotal, they may be helpful in creating disaster plans and guiding further research. Five main event-specific determinants were identified from these reports:

1. The threat of contagion. Nearly every interviewee identified illnesses that are contagious as much more likely to cause fear and absenteeism among healthcare workers, because the level of the contagion determines not only the risk that a healthcare worker faces but also the risk of then transmitting the disease to family members. One interviewee also mentioned that SARS was particularly disconcerting for healthcare workers because it was not only contagious but was being spread by and among healthcare workers.

2. The spread of disease in the local community. A number of interviewees emphasized that diseases spreading through a community would both increase the level of fear among healthcare workers, leading to additional absenteeism, and result in some healthcare workers refusing or being unable to work because family members were sick.

3. Availability of a vaccine and prophylaxis or treatment. This determinant was also mentioned by many interviewees as a central concern, because the availability of a vaccine and treatment impacts both the risk that healthcare workers face and the level of fear that they are likely to feel. This factor played a major role during a small monkeypox outbreak that occurred in the Midwest in 2003. A number of healthcare workers refused to care for monkeypox patients because they had not received the smallpox vaccine (Anderson et al. 2003).

4. The seriousness of the illness. Not surprisingly, interviewees felt that employees were more likely to be absent in an epidemic of a fatal illness. Some interviewees predicted increased absenteeism if a significant number of patients were dying.

5. The scope of the biological event. This determinant is particularly relevant to a bioterrorism scenario. For example, even if they were not exposed, outdoor aerosol dissemination of anthrax would likely have more of an impact on healthcare workers than the anthrax mailings due to the greater possibility of exposure.

As part of the study, survey data and interview results were examined to determine whether different groups of staff might be more or less likely to report to work during a biological event. Though some survey data address this issue on some level, other demographic divisions were not analyzed. Two surveys found that males are substantially more likely to report willingness to work during an epidemic (Masterson et al. 2008, Qureshi et al. 2005). In addition, Qureshi et al. (2005) found that physicians and emergency medical technicians were more likely to report willingness to work than other job classes. 
Interestingly, being married to a first responder also increased willingness to report to work (Qureshi et al. 2005).

While the interviews did not explore the question of gender, the interviewees identified five employee characteristics that might impact the likelihood of absenteeism:

1. Having children, especially young children. Several interviewees identified the risk of infecting children as a major concern to healthcare workers during SARS. This concern also appeared to be a major issue for healthcare workers involved in the monkeypox outbreak (Reynolds 2004). As one physician reported by Reynolds put it, "Next time, let somebody without kids handle this."

2. Perception of need. A number of interviewees mentioned that they felt nonclinical staff were more likely to be absent than clinical staff because they would see their work as less essential in a disaster.

3. Experience with infectious disease. Several interviewees mentioned that clinical employees might be more likely to report to work because they are more accustomed to the risk of infectious disease.

4. Commitment to their employer and their job. A number of interviewees mentioned that job satisfaction, as well as commitment to and trust in the employer, might impact healthcare workers' willingness to report to work. The level of trust that employees have in their employer is especially important, because they are counting on their employer to protect them during a biological event. Some interviewees suggested that staff that had been with the organization longer might be more committed, and thus more likely to report to work during a biological event. However, one EMS administrator argued that this would not necessarily be true, because younger employees might be more eager to prove themselves during a biological event. In either case, however, employee attitudes towards their employer and prior organizational culture may play a key role in employees' decisions about whether to attend work during an emergency.

5. Commitment to colleagues. A number of interviewees emphasized that commitment to other staff, or unit cohesion, plays an even larger role than commitment to the employer. As one EMS administrator put it, "A lot of people will come to work because they don't want to let their small team down." The importance of commitment to colleagues played an especially large role in the response to SARS. In that situation, healthcare workers did not want to disproportionately burden their colleagues by absenting themselves from work (Masterson et al. 2008, Reid 2005). Thus, the concept of personal risk had less to do with their choice. Reid (2005) expresses this crucial point in comparing physicians' responses to HIV and to SARS:

"The choice is not between past risk levels and current risk levels, but between accepting current risk levels and passing them on to someone else - and particularly, because of the elevated risk for healthcare workers, that 'someone else' during SARS was not a hypothetical doctor, whom the HIV-positive patient was left to find on his own, but a known colleague in the hospital setting" (Reid 2002).

In addition, because many of the people who contracted SARS were themselves healthcare workers, their colleagues had additional motivation to report to work. As one interviewee put it, "I think healthcare workers were galvanized to respond because they were taking care of their 
own-it was healthcare workers who were affected, so they couldn't abandon (their colleagues) in their time of need."

\subsection{Cultivating a Duty to Treat}

Though these event-specific and employee-specific factors are likely to affect the responses of healthcare workers in a biological event, a model for predicting absenteeism should not be fatalistic. Individual healthcare workers and leaders in the healthcare field have substantial agency to improve the healthcare response to a biological event. Thus, the survey data on healthcare worker absenteeism should be regarded not as general planning assumptions but as a worst-case scenario.

The example of HIV demonstrates that a "duty to treat" can be cultivated even in the absence of professional regulations or legislative fiat. Over the last 20 years, professional culture appears to have changed substantially. The survey data from the late 1980s about HIV is, in fact, similar to more recent data about biological terrorism and pandemic influenza. In a 1988 article, Link et al. found that $25 \%$ of New York house officers surveyed would not continue to care for HIV patients if given the choice, and $48 \%$ of medical house officers reported moderate to major concern about contracting HIV. Furthermore, $24 \%$ of all house officers felt that refusing to care for AIDS patients was not unethical; $34 \%$ felt that house officers should be allowed to decide for themselves whether to treat AIDS patients, and 53\% felt medical students should have this choice (Link et al. 1988). A national survey of physicians found similar results $-68 \%$ of respondents felt that they had a responsibility to treat HIV patients, but $50 \%$ said they would not treat HIV patients if they had the choice (Gerbert et al. 1991). Surveys also revealed substantial homophobia. In one survey at an urban teaching hospital, 10\% of nurses and house officers surveyed agreed that homosexuals who contract AIDS are getting what they deserve (Douglas et al. 1985).

In recent years, healthcare workers' attitudes towards HIV/AIDS appear to have changed substantially. Even surveys from later in the 1990s indicate changing attitudes towards HIV. In a 1996 article, Carter et al. surveyed Chicago medical students and found that $92 \%$ of those surveyed agreed that patients with HIV would be welcome in their medical practices (Carter et al. 1996). Another survey compared the Class of 1991 with the Class of 1994 at several medical schools and found that the Class of 1994 reported lower fear of infection and greater willingness to treat HIV patients; both fear of infection and willingness to treat were also correlated with having had greater contact with HIV patients (Anderson et al. 1997). Though more recent survey information on HIV was not found, based on anecdotal reports, it appears that the trend towards willingness to treat HIV patients has continued.

These changes might be explained in several ways. The increased willingness to treat HIV patients may result in part from greater knowledge and education, which leads to fewer concerns about the risk of contracting HIV. However, the survey data suggest that the reluctance to treat HIV patients did not stem solely from inflated perceptions of risk. Link et al. (1988) found that $80 \%$ of house officers surveyed estimated their chances of acquiring HIV to be equal or less than $1 / 10,000$. Thus, it appears that changes in professional culture, as well as increased knowledge, have affected the willingness to treat HIV. Epidemiological trends may also have helped decrease the stigma of the disease, as HIV has expanded beyond the stigmatized populations of homosexuals and intravenous drug users.

Of course, it is also possible that the survey data did not accurately reflect the way medical students or physicians actually responded to HIV/AIDS, just as the survey data about bioterrorism, SARS, or 
pandemic influenza may not accurately reflect how healthcare workers will actually respond. In some sense, it seems surprising that surveys would overestimate absenteeism-one might expect that healthcare workers would be reluctant to admit that they would refuse to work, even in an anonymous survey. However, a number of interviewees felt that healthcare workers would be more likely to report to work during an actual biological event as opposed to a hypothetical scenario because the needs of patients and colleagues would be starkly apparent.

These are by no means ironclad explanations. The discordance between the survey data and actual behavior remains an unresolved question that requires further research. To avoid the scenarios that the survey data present, employers must work to cultivate a duty to treat among healthcare workers. The responsibility for creating and maintaining this attitude falls on professional organizations as well as on individual hospitals. Though a healthcare worker's current employer certainly plays a key role in emphasizing the duty to treat, this attitude must also be cultivated as a characteristic of the profession and reinforced throughout clinical training. The American Medical Association (2004) has affirmed that physicians have a duty to treat during disasters:

"National, regional, and local responses to epidemics, terrorist attacks, and other disasters require extensive involvement of physicians. Because of their commitment to care for the sick and injured, individual physicians have an obligation to provide urgent medical care during disasters. This ethical obligation holds even in the face of greater than usual risks to their own safety, health or life. The physician workforce, however, is not an unlimited resource; therefore, when participating in disaster responses, physicians should balance immediate benefits to individual patients with ability to care for patients in the future."

A number of interviewees in the current study emphasized that, while healthcare workers do have a duty to treat patients during a biological event, they cannot be expected to respond unless their needs are met. 


\subsection{Meeting the Needs of Healthcare Workers}

Interviews and background research revealed eight key areas that policymakers and planners can target to minimize absenteeism and maximize the effectiveness of healthcare workers during a disasterleadership, communication, training, personal protection, practical needs (e.g., childcare), psychosocial needs, human resource policies, and liability concerns. These issues are discussed in the following subsections along with system-level changes that may be needed to address these needs.

\subsection{Leadership}

Nearly all of the interviewees identified effective leadership as essential during the response to a biological event. As one infectious disease specialist put it, "The bottom line is that, with good leadership and unit cohesion, people will find a way to show up to work. Otherwise, they will find an excuse not to show up." Several other interviewees also suggested that employees' general level of confidence in their leadership would have more of an impact on absenteeism than the exact policies.

Interviewees described three main leadership groups that would be important during a biological event. The first group is senior leadership, such as the hospital Chief Executive Officer and Chief of Medicine, who must ensure that the operations of the hospital are adjusted both to respond to the emergency and to meet the changing needs of staff. The second group comprises subject matter expects, such as infectious disease physicians and nurses, who can provide accurate information to staff on the risks that they face. The third group is unit-level leadership, representing the informal networks of leadership among co-workers in which certain people become trusted leaders in the absence of any explicit hierarchy. In some cases, these unit leaders may also be the unit managers, but in other cases they may simply be healthcare workers in whom others place their trust.

One interviewee highlighted confidence in senior leadership as a major challenge during the SARS epidemic in Toronto. This confidence impacted not only the ability of hospitals to respond effectively but also their ability to recover and resume normal operations. The SARS Commission Final Report (Campbell 2006) also mentioned that maintaining the trust of staff was particularly challenging at one hospital where the senior leadership was quite new. Though they responded competently, they had not had time to win the trust of their employees fully, and thus these employees lost confidence in their leadership much more quickly (Campbell 2006).

The importance of subject matter experts was exhibited in every case study associated with the research review, though it appeared to be most important when the risk to healthcare workers was most unclear. One infectious disease specialist in the current study recounted the role of subject matter experts during hospital preparations for a group of suspected Lassa fever patients. The unknown and frightening nature of this disease made it crucial to brief staff on the disease and measures being taken to protect them.

Though the role of unit-level leadership is sometimes harder to determine because its effects occur on a smaller scale, a number of interviewees emphasized that direct, personal leadership was in fact most important. One physician recalled the importance of unit-level leadership during the early years of the HIV epidemic when many healthcare workers were reluctant to care for HIV patients. He described how the food delivery staff would refuse to enter the rooms of HIV patients and instead leave the food sitting 
outside the door. Though there was no effort to sanction them through official channels, the head nurse managed to cajole them into delivering the food directly to the patients. This example illustrates the success of unit-level leadership in solving a problem that would have been difficult to address at the level of senior leadership.

The research survey showed that the impact of leadership on the response to a biological event was most pronounced in the developing world where fewer institutional controls and less reliable information were often available to staff. A plague outbreak in Surat, India, in 1994 offers an example of the disastrous impact of a lack of leadership. The absence of effective leadership from both the government and the hospitals led to widespread panic among healthcare workers and among the general public. Rumors and fear about the epidemic spread far faster than the disease ever could and over 600,000 people, including many physicians, immediately fled the city (Ramalingaswami 2001).

The extent of this panic is particularly striking given that plague is now a treatable disease. By contrast, the somewhat celebrated example of Dr. Matthew Lukwiya's actions during an ebola epidemic in Northern Uganda offers an example of the power of good leadership, even in the face of a deadly and poorly understood disease. Despite the deaths of a number of his staff, Dr. Lukwiya maintained their commitment and effectiveness until he eventually contracted ebola and died (Harden 2001). ${ }^{1}$

Though these examples may not translate directly to the experience of American hospitals, they do present a number of issues that American hospitals will need to confront. The challenge of information availability and the trust of staff in the information conveyed may be a particular challenge for small hospitals and EMS organizations because they will not necessarily have subject matter experts onsite.

Dr. Lukwiya's tragic death also demonstrates the need for continuity plans that address the possibility that hospital leadership may become incapacitated. Hospitals must also balance the ability of leaders to set an example by serving in the wards with the need to protect them from infection. During the SARS epidemic in Toronto, some hospitals decided that their senior leadership had to be separated completely from the clinical wards. Though this undoubtedly helped prevent senior leaders from becoming infected, it also hampered their ability to inspire confidence in their staff. The determination of which leaders should stay in the wards and which should be separated will vary from hospital to hospital, but hospitals must plan to address this issue.

\subsection{Communication}

Effective communication represents another need of healthcare workers during a biological event. While communication is certainly part of good leadership, it is addressed separately in this report for the sake of clarity. Nearly all interviewees mentioned the importance of frequent, accurate, and honest communication, and many stressed the role that preexisting communication plans can play during a disaster. ${ }^{2}$ Providing consistent, compassionate, and accurate communication to the entire staff, with opportunities for the staff to provide feedback, will help hospital leadership acquire and maintain the trust of their workforce.

\footnotetext{
${ }^{1}$ Dr. Lukwiya's tragic death also highlights the delicate balance between having leaders set an example by serving on the wards and protecting them from infection.

${ }^{2}$ A number of resources are available from the Centers for Disease Control and Prevention on crisis communication. An excellent starting point is Reynolds et al. (2002). See also Lundgren and McMakin (2008).
} 
Of course, the first step in communicating well with employees is obtaining accurate, up-to-date information. For large hospitals, subject matter experts can provide some in-house expertise, but healthcare facilities can rely on local, state, and federal public health agencies as well. During the SARS epidemic in Toronto, poor communication between public health officials and hospitals represented a major barrier to the SARS response. Public health officials did not have a comprehensive listing of physicians in the Toronto area and thus had to turn to the Ontario Medical Association to disseminate an alert about SARS. However, the Ontario Medical Association did not have complete contact information for all physicians and did not have any way of contacting other healthcare workers (Campbell 2004). Family physicians were largely neglected during the SARS response, and their lack of infection control expertise made them particularly vulnerable to SARS. Likewise, nurses were made to feel that public health officials valued them less than physicians, because they were not notified in as timely a manner about SARS precautions. Thus, Toronto Public Health's lack of a complete communication plan not only put healthcare workers at risk but also decreased staff morale. ${ }^{3}$ Furthermore, hospitals did not have assigned points of contact, or any kind of "direct line" to public health officials; thus, hospital officials ended up on hold, like any other private citizen (Campbell 2004).

Together, these barriers not only hampered collaboration between public health officials and hospital leadership but also made it difficult for hospital administrators to obtain real-time information to disseminate to their staff. One interviewee in the current study commented that sometimes information would be on television before it had been fully distributed to staff, even within Toronto Public Health. In addition, hospitals sometimes ended up distributing out-of-date information to their staff, which left staff with the impression that their leaders were either incompetent or intentionally keeping them in the dark.

The problem of poor communication links between public health and healthcare facilities is by no means unique to Toronto. The 2001 Capitol Hill anthrax attacks revealed the same challenges in Washington D.C. Physicians reported hearing information on CNN because they had no other means of obtaining it (JCAHO 2003). Thus, it is imperative that public health officials work with hospitals and EMS units to develop formalized communication plans ahead of time.

Hospitals must also ensure that they have the ability to communicate information to their staff in a quick and reliable fashion. Though the exact means of doing so are beyond the scope of this report, interviewees emphasized the importance of using multiple methods, including telephone information lines, mass emails, text messaging, leaflets, and "town meetings" where employees could ask questions and express concerns. ${ }^{4}$ One infectious disease specialist also said that he had put together threat agent fact sheets for his hospital so that they would be ready to distribute in an emergency. During the SARS epidemic in Toronto, hospital management often failed to communicate effectively with their employees. Some quarantined employees did not know that their coworkers were sick and might have exposed them to SARS, nor were they told to isolate themselves from their families (Campbell 2006). These difficulties, which posed unacceptable risks to the families of quarantined healthcare workers, could have been prevented through better communication planning.

\footnotetext{
${ }^{3}$ The Toronto Public Health officials should not bear all the blame. A wide range of factors played a role in producing these communication failures, not the least of which was the government's lack of investment in public health. It must be stressed that these were system-level failures rather than human errors.

${ }^{4}$ The National Incident Management System contains guidelines for effective coordination of crisis communication under the Joint Information System and Joint Information Center model.
} 
A final point that many interviewees stressed is maintaining the credibility of communicators. They emphasized the importance of providing immediate updates if information changes, so that staff did not find out through other channels first, as well as acknowledging the gaps and uncertainties in current information. During the second phase of SARS in Toronto, public health officials and hospital leaders insisted that SARS was gone. When it turned out that SARS had remained, many hospital employees felt that the hospitals had betrayed their trust and put their lives at risk needlessly. Though the public health and hospital officials were acting on their best judgment at the time, their excessive certainty in claiming that the SARS epidemic had run its course was ultimately harmful (Campbell 2006). The perception, even if incorrect, of political influence on these communications also had a devastating impact on the credibility of the communicators and the morale of healthcare workers (Campbell 2005).

The response to the September 11, 2001 attacks featured similar challenges, including the nowinfamous assertion by former U.S. Environmental Protection Agency Administrator Christine Todd Whitman that the air in lower Manhattan was safe to breathe. Allegations of political influence, whether founded or unfounded, further eroded trust in the government's communication efforts (DePalma 2007). Because of its long-lasting impact on employee trust, communicators must make every effort to avoid any appearance of undue political influence.

\subsection{Training}

Another key need identified by nearly all interviewees in the current study was pre-event training. Because of existing fears about biological agents, especially the agents that might be used in an attack of biological terrorism, education about potential threats should be a central component of training programs for healthcare workers. In a national study conducted in 2006, Alexander et al. found that only $56 \%$ of emergency physicians and 33\% of primary care physicians had received any training on bioterrorism response. Interviewees in the current study emphasized that training aimed at increasing employee knowledge of particular diseases will help dispel anxieties that are not based in actual fact, but simply in fear and uncertainty. One interviewee mentioned that such training had been essential in addressing the concerns of first responders about HIV exposure. Other interviewees discussed how they rushed to provide training about anthrax during the 2001 Capitol Hill anthrax attacks to alleviate the fears of healthcare workers about this unfamiliar threat.

Interviewees also found personal emergency preparedness training to be important. One interviewee involved in public health discussed how he and his colleagues had organized a preparedness fair for their whole agency in which they focused on personal preparedness. They believed that encouraging and assisting employees in making disaster plans for their families would increase the functioning of their agency during a disaster because employees would be much more willing to come to work if they knew that their families were well prepared. They also hosted a follow-up event with the Society for the Prevention of Cruelty to Animals and the Red Cross that focused on pet care during disasters, since many employees had asked questions about this topic at the original preparedness fair. One physician mentioned that his hospital had taken similar steps, providing employees with templates and checklists for disaster plans and collecting information on employees' childcare needs.

Several public health and hospital officials also commented on the importance of training employees on how the health department or hospital will function during a disaster. Employees should be trained on what it means to be an essential worker to encourage employees to come to work. One hospital official 
also mentioned that she had worked with the media to clarify this idea as well, so that the media would make it clear that healthcare workers and emergency responders should come to work during situations when news stations encouraged non-essential workers to stay home. Several interviewees also stressed that employees need to understand the chain of communication during disasters, so that they know how they will be notified of changes in shift schedules or reassignment to different locations.

Because of the rapid pace of a crisis situation, just-in-time staff training is simply not an optionhospitals and EMS agencies must invest in significant training ahead of time. During the SARS epidemic in Toronto, few plans were in place to address who would be involved or how they would be involved in the crisis response. This deficiency led to both confusion and resentment, because the rushed process of allocating staff lacked a sense of equity. Some employees assigned to support the SARS response felt that this assignment implied that their normal work was less important or were bothered by the inconveniences and challenges that it posed (such as working at different locations or on different schedules). In light of these difficulties, all organizations involved in healthcare should have a business continuity plan and ensure that employees understand how different aspects of this plan affect them.

Finally, several interviewees emphasized that training must be available and accessible to all employees. In hospitals, non-clinical staff are sometimes overlooked in disaster drills. However, a number of interviewees mentioned that they would expect the highest rates of absenteeism among nonclinical staff, making outreach and education directed at this group essential to the functioning of the hospital during a disaster. Developing training programs targeted at staff who are not native English speakers is also essential in reaching another group of employees who otherwise receive less information and education. Finally, hospitals must ensure that disaster training and drills occur during the night shift as well as the day shift — one study of U.S. hospitals found that most drills occurred during the day shift (Braun et al. 2006). Given that a biological event will require a continuous, round-the-clock response effort, night shift employees must receive equal training and preparation.

\subsection{Personal Protection, Prophylaxis, and Security}

The scientific details of the use of personal protective equipment (PPE) and drug prophylaxis during a biological event are beyond the scope of this report. However, key issues of management and communication surrounding PPE and prophylaxis surfaced during the interviews. A number of interviewees emphasized that employees must not only be well protected, but must feel that they are wellprotected to ensure their attendance.

Prior training and fit testing on PPE are essential in bolstering employees' confidence during a biological event. For this reason, hospitals must maintain adequate infection control staff to provide this training and assist with employee concerns. Because this training is rarely put into use, simplicity in PPE protocols becomes paramount - overly complex or varied protocols cause confusion and can lead to mistrust among staff, as occurred in some hospitals during the SARS epidemic in Toronto (Campbell 2006). In addition, interviewees in the current study emphasized the importance of communicating other protective measures to employees ahead of time to demonstrate the efforts being made to protect them. One EMS administrator discussed their system of tracking respiratory calls so that a spike would allow them to increase PPE levels immediately. He also mentioned that the department kept stockpiles of pharmaceuticals for its workers and emphasized that these measures were important not only in assuring 
preparedness but also in creating "a general understanding among our workforce that [the department] will do whatever [it] can to take care of them."

Interviewees also emphasized the importance of a well designed plan for distributing drug prophylaxis during a biological event. One physician discussed how his hospital had created an automated decision support tool, which would allow uploading of relevant employee medical data that would be used to make quick decisions about what sort of prophylaxis to give each employee. Several interviewees stressed the importance of providing prophylaxis not only for employees but for their families as well. This additional step will make staff feel protected and create an incentive for them to show up to work, since showing up will allow them to obtain medications for their families. One challenge that hospitals, EMS units, and public health agencies will all face is the question of how to allocate scarce medications. In discussing pandemic flu planning, Vawter et al. (2007) argue that healthcare workers' families and even healthcare workers in low-risk settings should not be given priority. While the scientific and ethical considerations are complex, it is worth considering that healthcare workers who are caring for low-risk patients may still feel that they are at an elevated risk and may be reluctant to come to work if they do not receive prophylaxis. Whatever conclusions different hospitals and agencies draw, it is important to remember that employees will closely scrutinize all decisions and communication about PPE and prophylaxis.

Another issue that receives comparatively little attention is the negative impact of social disruption and lack of security on attendance during disasters. One interviewee recounted an experience during the Katrina response in which a federal Disaster Medical Assistance Team abandoned its post because its members felt unsafe at the Superdome. Numerous examples of security concerns appeared postKatrina - as one physician wrote, "I was never afraid of wind, water, fire, hunger, or disease. My moments of fear came when I was confronted by agitated, fearful human beings bearing firearms" (Berggren 2005). She went on to document specific instances of violence, "My husband was exposed to sniper fire twice while helping to evacuate the emergency room dock. People with guns shut down an entire hospital evacuation for many hours." Other authors have also documented security concerns postKatrina (e.g., Bluth et al. 2007). While a biological event might not generate the same level of social disruption as Hurricane Katrina, several interviewees mentioned that situations in which medication was limited (such as pandemic influenza) could prove particularly volatile. Hospitals, EMS units, and public health agencies should each address unique security concerns in their emergency plans.

\subsection{Practical Needs}

In addition to the more dramatic consequences of social disruption, the interruption of everyday services, such as childcare, eldercare, and transportation, could have a large impact on the ability and willingness of healthcare workers to report to work. All healthcare institutions must address these issues, both to ensure the short-term functioning of the institution and to maintain the long-term loyalty of their employees. As one physician put it, "Hospitals need to invest in their healthcare workers...it is important that they feel it is within their mission to do this."

Interviewees offered a number of ideas and plans for meeting the practical needs of their employees. Some mentioned creation of an emergency childcare or dependent care unit within the hospital during emergencies. In an account of Hurricane Katrina, Robert Aucoin (2006) also mentions that this option worked quite well. Others, however, were concerned that this option would not be practical or desirable 
in the specific case of a biological event. One physician instead suggested that hospitals develop "memoranda of understanding" with the hospitality industry, so that employees could bring their children and dependent elders to a hotel where the hospital would set up a dependent care center. For employees who live a significant distance away and have difficulty commuting home during the emergency because of transportation disruptions or changes in shift schedules, hospitals could also arrange temporary lodging at the same hotel. ${ }^{5}$

Regardless of which approach is most feasible for a given hospital, interviewees emphasized the importance of early preparation. One interviewee recommended that all institutions collect information on employees' dependents so that children and dependent elders would already be registered in a system which documents emergency contact information for their caretakers as well as any specific needs they might have. This physician also mentioned that they had distributed educational materials regarding emergency supply kits that parents could assemble for their children.

These efforts to meet the material needs of healthcare workers would gain additional importance in the event of a work quarantine, in which healthcare workers were asked to limit their contact with the general public to minimize the risk of community spread of a disease like SARS. In Toronto during the SARS epidemic, public health officials and hospitals took measures, such as chartering buses for healthcare workers, so that they would not have to take public transportation. Public health officials also worked hard to meet the needs of healthcare workers under home quarantine (those who had been exposed to a SARS patient), though they encountered difficulties in trying to implement a system during the epidemic.

According to interviewees in the current study, another major concern that surfaced during the SARS epidemic was the fear of infecting family members. Both quarantined employees and those who were actively taking care of SARS patients expressed fears about transmitting the disease to their families and would have appreciated the option of living somewhere else temporarily. Providing these employees with other options, such as moving into a designated hotel during quarantine or sleeping at the hospital, might have helped alleviate these concerns, though each of these options has its own drawbacks. However, the ability to keep healthcare workers' families safe may be the most significant determinant of willingness to work, so this area requires further research and planning by hospitals and public health departments.

In addition to these major categories of needs, interviewees also suggested that paying attention to the little things matters a great deal. A number of the interviewees stressed that small gestures by management, such as providing employees with food and allowing them to use long-distance phone lines to contact family members, can have a substantial impact on staff loyalty and dedication. Such gestures can also help recognize the importance of the employees' work.

\subsection{Psychosocial Needs}

Though addressing the psychosocial and mental health needs of healthcare workers is important in any disaster, the likelihood of a protracted response effort to a biological event will make effective psychosocial support paramount in ensuring both the well being of healthcare workers and the continued

\footnotetext{
${ }^{5}$ While most interviewees felt that transportation difficulties would be less of a problem during a biological event than during other natural disasters, a number mentioned that they keep track of where their staff live so that they could efficiently arrange carpools if needed for those who usually take public transportation.
} 
functioning of healthcare institutions. After the SARS epidemic, researchers in Taiwan (Chen et al. 2007), Hong Kong (Chua et al. 2004), Singapore (Koh et al. 2005), and Canada (Maunder 2004, McAlonan et al. 2007, Styra et al. 2008) all documented significant stress, anxiety, and depression among healthcare workers. However, researchers in Toronto did not find any evidence that the SARS epidemic produced an increase in serious psychiatric disorders (Lancee et al. 2008). Thus, the more temporary anxiety and depression produced by SARS may be more amenable to intervention.

In addition to managing their own fears of infection, healthcare workers treating SARS patients also had to confront the tragedies that their patients were facing - especially since SARS often spread through families. One interviewee discussed how the Toronto public health nurses doing case management often became quite attached to the families with whom they were working and were quite upset when patients died. At the time of the epidemic in Toronto, few plans were in place for addressing the mental health needs of healthcare workers - though the public health department did employ mental health nurses, they were not used to working with their colleagues, which limited the effectiveness of the ad hoc employee assistance programs that were implemented.

While many hospitals have mental health resources for staff, it is important to consider how to accommodate a large increase in requests for assistance. In addition, in a situation where a disease is being transmitted person-to-person, hospitals may face the dual burden of meeting the needs of working employees while also supporting employees who have become ill. During the SARS epidemic in Toronto, healthcare workers ill with SARS often felt isolated or unsupported. Hospitals did not have plans to meet the needs of sick healthcare workers, and their colleagues had difficulty contacting them or obtaining information about their condition (Campbell 2006). Though hospitals were understandably concerned about protecting the privacy of sick employees and the confidentiality of their medical information, these efforts had the unintended consequence of decreasing the availability of social support.

It is also important to recognize that employees who become ill may face substantial emotional challenges when returning to work. During the SARS epidemic in Toronto, very few of the staff who fell ill were comfortable coming back to work immediately after they recovered physically. Several interviewees in the current study also emphasized the psychological burden that the families of ill healthcare workers faced and argued that hospitals must make more effort to support these families. They pointed out that fire departments have, in the past, done this much more successfully than hospitals.

The impact of stigma represents another challenge in responding to an epidemic of a contagious disease. After the SARS epidemic in Singapore, researchers found that $49 \%$ of the healthcare workers interviewed felt shunned because of their jobs, and $31 \%$ had experienced ostracism by family members. In addition, $31 \%$ felt that their families had suffered from stigma by association (Koh et al. 2005). Anecdotal reports described healthcare workers being stigmatized and shunned in Toronto as well (Campbell 2006, Hall et al. 2003). While hospitals may have little control over public reactions to infectious disease, they can nonetheless take steps to support employees both privately and publicly to minimize the negative impact that such stigma has on healthcare workers. Public health agencies can also take steps to educate the public and address groundless fears about healthcare workers. 


\subsection{Human Resource Policies}

Human resource policies play a crucial and often overlooked role in disaster response, particular in a biological event. One human resource issue that arose during the SARS epidemic was the use of students in academic medical centers. One interviewee in the current study discussed the limited planning to integrate students into the outbreak response. As a result, all students were sent home. While the hospitals did so in part to protect their students, in the future students should be engaged in a productive fashion while also being protected to a certain extent. For example, fourth-year medical students could be quite useful in case management and contact tracing for exposed patients. ${ }^{6}$

More broadly, healthcare institutions must also consider what options they have under employment contracts and local regulations to change their staffing model during a disaster. Such options could include cancellation of vacations, reassigning staff to different job functions or different locations, increasing the length of shifts, using non-union employees, and using retired staff. The issue of sick leave, especially in the event of a contagious epidemic, must also be handled in advance. Hospitals must determine who will decide whether an employee should be sent home because of illness, when ill or quarantined employees can return to work, and whether sick or quarantined employees will continue to be paid even if they use up all of their paid leave. During the SARS epidemic, payment during quarantine was a major concern for healthcare workers; though the government eventually agreed to pay all healthcare workers during quarantine, this policy remained unclear until late in the epidemic (Campbell 2006). ${ }^{7}$ Because these issues contain so many complexities that will vary from place to place, exact policies that hospitals should put into place are difficult to recommend. However, implementing a well planned and equitable system of assigning job responsibilities will be essential in preserving the morale and loyalty of staff.

The interviewees in the current study also emphasized that compensation during disasters will play a large role in determining how employees react. While normal rules about overtime would presumably still apply, challenges may arise if different groups of employees receive different benefits. For example, if nurses paid by the hospital receive a better overtime pay structure than nurses employed by a contract, the contract nurses may be reluctant to work longer shifts, especially during a difficult and perhaps dangerous biological event. Interviewees in the current study also consistently highlighted the unresolved issue of hazard pay - should employees who are caring for patients with a disease like SARS or pandemic influenza receive additional compensation because of the risk incurred? While some interviewees thought that providing hazard pay might encourage employees to report to work, others were concerned about applying this policy equitably among different groups of staff and across hospitals. ${ }^{8}$ Some interviewees were also concerned that providing hazard pay or life insurance could send the wrong message, giving employees the perception that they were in greater danger than was actually the case. ${ }^{9}$

\footnotetext{
${ }^{6}$ The U.S. Centers for Disease Control and Prevention (2007) also mention the importance of defining the role of students in the CDC Pandemic Influenza Planning Checklist.

${ }^{7}$ Grace et al. (2005) found that $10.9 \%$ of physicians attended work despite having SARS symptoms, perhaps because they were concerned about losing income.

${ }^{8}$ Similar concerns arose in Taiwan during the SARS epidemic. Some hospitals chose to provide hazard pay, but doctors received an extra $\$ 300$ per day, while nurses received $\$ 150$ per day. Dwyer and Tsai (2008) have argued that this pay structure was inequitable because it did not correspond to the risk of exposure that employees faced-if anything, nurses were at greater risk of exposure.

${ }^{9}$ Some authors have argued instead for supplemental health insurance, since different employees may have a wide range of insurance schemes. Physicians and nurses may have supplemental insurance, whereas other healthcare
} 
Many of the interviewees highlighted the issue of determining the acceptability and consequences of employee absences. Most interviewees argued that threatening employees would be ineffective because, "It is easy for people to just call in sick, no questions asked." Thus, threats of consequences might simply push employees to lying in this way. Yet, as many acknowledged, attendance policies are difficult to maintain with no consequences. This conundrum has no easy answer, and most interviewees suggested a middle ground with consequences for egregious behavior while the main focus is placed on encouraging employees to come to work.

The adjudication of workers' compensation represents another central and unresolved challenge. This adjudication has been a major problem in the aftermath of the September 11, 2001 attacks, as New York City has aggressively challenged workers' compensation claims by people who worked at the World Trade Center site (Chan 2006). The New York Times' Anthony DePalma has also highlighted a disturbing lack of equity in the workers' compensation decisions: "Firefighters who have developed sarcoidosis since Sept. 11 are thought to have contracted the disease because of their work at ground zero. Yet the Police Pension Board has ruled that working at ground zero did not cause the death of a police officer who developed the disease" (DePalma 2006).

Trying to prove exactly how a healthcare worker contracted an illness could be similarly contentious unless reforms are instituted. In addition, given the publicity over the September 11, 2001 workers' compensation cases, healthcare workers may be less inclined to put themselves in danger unless they know that this issue has been resolved. A number of interviewees were quite concerned about this issue because of its potential impact on their employees and on the functioning of their organizations. One EMS manager summed up these concerns in direct terms:

I hope that the federal government will deal with this in a unified way and say that it is presumed that you contracted the disease in the line of duty. It will be very difficult to make these links in a pan flu situation unless there is presumptive legislation. Without these measures, a lot of the other things I try to do [to ensure that employees report to work] won't matter.

A number of interviewees emphasized that ensuring equity among employees was the largest concern in all areas of human resource policies, rather than the exact details of compensation or consequences for absences. As one interviewee put it, "It doesn't really matter what the policy is, as long as it's fair and is perceived as fair." She stressed that this focus on fairness needed to extend even to small things, such as parking reimbursement and meal reimbursements, especially if staff are assigned to alternate facilities during a disaster. Though such issues may seem inconsequential, these choices send messages to employees about their value to the organization, just like larger decisions about compensation.

\subsection{Liability}

Though the complex details of this issue are beyond the scope of this report, it is worth noting that some employees may be concerned about liability during a biological event. In a large-scale event, some employees may be working outside their normal area of expertise, and, in the most drastic situations, hospitals may need to alter standards of care to manage a large influx of patients. These issues of liability

workers like technicians and clerks may not. Thus, in the interest of equity, they argue, an insurance fund for employees who fall ill should cover any gaps in their existing insurance (Singer et al. 2003). 
and altered standards of care were presented in stark fashion during a highly publicized case following Hurricane Katrina in which a doctor and two nurses were accused of euthanizing several patients. During the ensuing controversy, individual healthcare workers and professional societies strongly supported the accused healthcare workers, and some argued that the district attorney, and, by extension, the Louisiana government, were grandstanding to distract from the abject failure of the evacuation and the government's response to the hurricane (Okie 2008). Though the grand jury eventually declined to indict any of the three healthcare workers, a civil suit remains in process. This case demonstrates the potential for recriminations and lawsuits following other disasters, and highlights the need for clearer regulation on situations that necessitate altered standards of care. Though liability restrictions may impose a cost on patients who are injured, they might also increase the willingness of healthcare workers to take care of patients during desperate times.

\subsection{System-Level Needs}

This report has primarily focused on the needs of individual healthcare workers. However, it is worth noting that the infrastructure of healthcare institutions and government must remain functional for healthcare workers to do their job. In hospitals, non-medical staff must continue working during an epidemic so that healthcare workers will be paid and hospitals must remain solvent. Thus, either the insurance reimbursement system must be functioning normally or the government must step in to assist the hospitals temporarily. ${ }^{10}$ EMS and public health agencies, which rely on local funding, might also exhaust their budget during a biological event and require state or federal assistance.

The question of which entities should bear the costs is also complex, because it is unclear exactly what events the Stafford Act covers. The Stafford Act is the primary legislation directing the federal government's response to disasters within the United States. The Act gives Federal Emergency Management Agency (FEMA) the responsibility for coordinating government-wide relief efforts, and authorizes the President to allow different levels of federal assistance to and intervention in states and localities based on the declaration of an event as an emergency or a major disaster. In the case of the 2001 anthrax attacks in Washington, DC, New York, and Florida, no request was made for emergency or major disaster assistance under the Stafford Act. The anthrax mailings were never declared a disaster by the federal government. As a result, individual hospitals bore a substantial part of the cost of the response effort. The role of private insurers will also create complexities because the emergency may dictate that patients be cared for by hospitals or physicians who are not part of their insurance plan. Sorting through these challenges will require cooperation among hospitals, insurers, and the government.

Finally, hospitals will not be able to function without a functioning transportation and commerce infrastructure. Deliveries of medical supplies must continue, and thus suppliers must be able to sustain their operations despite the disaster. ${ }^{11}$ Fortunately, a biological event is less likely to cause the

\footnotetext{
${ }^{10}$ Even if the insurance reimbursement system is functioning, hospitals may still require government assistance because they may need to cancel lucrative elective procedures to respond to the epidemic. As an example, St. Vincent's hospital in New York lost \$1.78 million as a result of canceled procedures during the immediate aftermath of the September 11, 2001 attacks, and the total event resulted in \$10.8 million in lost revenue (Feeney et al. 2005).

${ }^{11}$ One interviewee described how failures by medical suppliers could create havoc even under normal circumstances. Many suppliers do not allow hospitals to have secondary contracts, and the same suppliers often serve multiple hospitals in the same area. Thus, when one supplier in Washington lost its license to distribute narcotics, this caused medication shortages in local hospitals. The next closest supplier was in California and did not have a certification to distribute in Washington.
} 
widespread infrastructure interruptions that can be caused by a natural disaster. However, the lack of power, water, waste services, and supplies post-Katrina, and the impact on the ability of hospitals to provide care, should serve as a warning. Without a basic level of infrastructure functioning - electric power, water, transportation of supplies (both medical and non-medical essentials, such as food), availability of gasoline, and a functioning monetary system - hospitals and EMS agencies will be unable to mount an effective response to an epidemic. 


\subsection{Recommendations}

The sections above on the needs of healthcare workers have contained implicit and explicit recommendations about how to meet each need. Below, the necessary action steps are organized by the institutional actor who will perform them rather than by the need they address.

\subsection{Hospitals and EMS Organizations}

Because they are most directly responsible for the well being of healthcare workers, hospitals and EMS organizations must play the largest role in addressing the concrete needs of healthcare workers. First, hospitals and EMS organizations must constantly strive to develop good leadership, cultivate trust, and build the morale of their employees. A business continuity plan is also essential for ensuring that leadership remains functional even if individual managers are ill.

In addition, both hospitals and EMS units should identify subject matter experts who can satisfy the information and education needs of their staff during a biological event. All staff should also receive training beforehand on hospital emergency plans, biological agents, PPE, and personal and family preparedness. Hospitals and EMS organizations must also develop plans for communicating with staff during a disaster, encompassing communication responsibilities and message dissemination. Hospital leaders and unit managers should receive training on effective risk communication, because all of the leadership team will play a role in communicating with employees. Finally, training should emphasize essential worker designations, creating a culture in which all healthcare workers (including those providing nonclinical services) feel obligated to come to work because they understand the importance of their role in providing healthcare during a disaster.

Hospitals must ensure that they can provide sufficient supplies of PPE and medication to their staff. The distribution of PPE should include re-training of staff on its proper use (to supplement prior training). Hospitals should also collect information from staff on pre-existing medical conditions and contraindications, so that medication can be efficiently distributed during a biological event.

Hospitals should also assist staff in handling the disruptions that a biological event will cause. Employees may need assistance in finding options for childcare, eldercare, and pet care. Hospitals should consider whether they can provide childcare (and eldercare) onsite or at a nearby location in the event that normal childcare centers are closed or for staff who are working atypical shifts. In addition, hospitals may wish to consider whether they should provide housing for staff who do not wish to live with their families during the epidemic. Finally, if employees' normal transportation options are unavailable, hospitals should have plans to provide alternatives.

In addition, hospitals must have the capability to meet the psychosocial and mental health needs of their employees, including arranging for mental and behavioral health assistance at the hospital, developing plans to support infected staff, and anticipating other difficulties that staff may face, such as stigma within the community and the challenge of discussing the danger they face with their families and children. Some hospitals might also choose to implement other efforts, such as a buddy system that pairs experienced employees with less experienced employees to help them cope with the stress of the situation. 
Finally, hospitals should clarify their human resource policies and communicate them to staff before an actual event. As mentioned earlier, hospital leadership must have a clear understanding of the bargaining unit contracts, so that they understand the different systems of compensation and the flexibility they have in canceling vacations, changing shift schedules, reassigning employees to different locations or job functions, etc. These efforts may require collaboration and negotiation with unions, with both hospital and union leaders taking the initiative to work out the details before a disaster occurs.

In delineating the responsibilities of hospitals, it is also important to recognize the distinction between large academic medical centers and smaller community hospitals. Community hospitals may not have the resources to meet all of these recommendations. One weakness of the current study is that the physicians and other hospital leaders were almost entirely from large, urban teaching hospitals. Similarly, the EMS managers work in urban areas. Thus, these recommendations may not be entirely relevant or feasible in rural areas.

\subsection{Public Health}

In addition to meeting the needs of their own employees, public health agencies must also assist hospitals during a biological event. This support entails developing close linkages with hospitals ahead of time and creating plans for communicating with hospitals and healthcare workers during an event. Hospitals must have the ability to provide the latest information to their employees, so public health agencies need to ensure that they can provide all hospitals (and outpatient physicians) with accurate, upto-date information. Public health agencies must also serve as the central link between hospitals, outpatient providers, EMS organization, and other groups, such as funeral homes, whose input will be important during a biological event. Creating business continuity plans will be essential in ensuring that public health agencies can continue to perform these central functions even if some staff are absent.

\subsection{Government}

State and federal government must play a role in ensuring that the healthcare system as a whole is prepared for acts of biological terrorism or naturally occurring epidemics. First, the government must help hospitals fund disaster preparedness training. As one interviewee put it, "The basic problem is that market forces are pushing hospitals away from preparedness," because this training does not contribute to their financial success. In addition, the federal government should update the Stafford Act to include biological epidemics, so that hospitals are not responsible for the financial burden of these events. The relationship between hospitals and FEMA is also uncertain, because hospitals are deeply involved in disaster response and recovery but are not always well integrated into the disaster response system. Clarifying the communication structure between the healthcare system and the disaster response system will ensure the solvency of hospitals during crises and improve the disaster response system as a whole.

Federal leadership is also needed to handle the reimbursement issues that will arise during a largescale biological event. The federal government should create clearer guidelines for Medicare and Medicaid reimbursements during disasters and require that private insurance companies do the same. The challenges will be particularly acute for private insurance companies, because the exigencies of the emergency may require sending patients to physicians and hospitals that are not covered under the patients' normal insurance scheme. Government action will be crucial in creating a centralized plan to suspend normal restrictions and streamline reimbursement during a disaster. 
The Occupational Health and Safety Administration and the Centers for Disease Control and Prevention should standardize acceptable levels of PPE for different hazards. During the SARS epidemic in Canada, the lack of national guidelines resulted in individual hospitals having to determine the appropriate level of protection on their own (Campbell 2006). As suggested in the SARS Commission Final Report (Campbell 2006), OSHA and the CDC should also provide guidance on whether pregnant women and immunocompromised healthcare workers should continue to work during a contagious epidemic.

Though the government may be reluctant to address these issues, establishing guidelines for altered standards of care and limiting medical liability can only be accomplished at the state or federal level. Though these might both be politically charged issues, several of the interviewees in the current study thought that national standards of care would improve the ability of the medical system to respond to a major epidemic or other disaster.

In addition to providing specific guidelines on standards of care, the federal government should act as a central information source for hospitals, EMS organization, and local public health agencies. While some interviewees recognized the work of the CDC, the Department of Homeland Security (DHS) and Health and Human Services (HHS) in providing user-friendly information, several interviewees argued that the federal government could do more to support local agencies. DHS and FEMA have collaborated to create a Lessons Learned and Information Sharing (LLIS) website, an encrypted site that allows verified emergency response providers to access a wide range of materials and reports related to terrorist threats and other incidents. ${ }^{1}$ However, many local emergency planners and public health officials may not know about the resources that LLIS provides. In addition, the LLIS system may be more relevant to state and federal officials than to EMS and hospital administrators or local public health officials. Thus, while the LLIS system represents a key advance in this field, DHS should continue to strive to publicize this resource and tailor it to address the needs of all the groups involved in emergency planning.

\footnotetext{
${ }^{1}$ United States Department of Homeland Security, "Lessons Learned and Information Sharing," www.llis.dhs.gov accessed March 16, 2009.
} 



\subsection{Conclusions}

This report provides a needs assessment for emergency planners throughout the healthcare system. In addition, it compiles the wisdom and concerns of on-the-ground emergency planners to provide a resource both to other emergency planners and to policymakers who strive to prepare this country for the twin dangers of biological terrorism and emerging infectious disease. Healthcare workers are the nation's most valuable medical resource. Their willingness to come to work and risk their own safety will allow the medical system to minimize the harm that others suffer during one of these tragic events. Because of their dedication to preserving the lives of others, healthcare workers deserve the utmost effort to ensure their safety and well-being during disasters. May this report play at least a small role in advancing this cause. 



\subsection{References}

Alexander GC, GL Larkin, and MK Wynia. 2006. "Physicians' Preparedness for Bioterrorism and Other Public Health Priorities." Academic Emergency Medicine: Official Journal of the Society for Academic Emergency Medicine 13(11):1238-1241.

Alexander GC and MK Wynia. 2003. "Ready and Willing? Physicians' Sense of Preparedness for Bioterrorism." Health Affairs (Project Hope) 22(5):189-197.

Altman LK. March 21, 2003. “Asian Medics Stay Home, Imperiling Respiratory Patients.” The New York Times.

American Medical Association. 2004. “Opinion 9.067 Physician Obligation in Disaster Preparedness and Response." Code of Medical Ethics. American Medical Association, Chicago, Illinois. Assessable at: http://www.amaassn.org/ama1/pub/upload/mm/Code_of_Med_Eth/opinion/opinion9067.html.

Anderson DG, C Vojir, and M Johnson. 1997. "Three Medical Schools' Responses to the HIV/AIDS Epidemic and the Effect on Students' Knowledge and Attitudes." Academic Medicine: Journal of the Association of American Medical Colleges 72(2):144-146.

Anderson MG, LD Frenkel, S Homann, and J Guffey. 2003. "A Case of Severe Monkeypox Virus Disease in an American Child: Emerging Infections and Changing Professional Values." The Pediatric Infectious Disease Journal 22(12):1093-1096; discussion 1096-8.

Arras JD. 1988. "The Fragile Web of Responsibility: AIDS and the Duty to Treat." The Hastings Center Report 18(2):S10-20.

Aucoin RG. 2006. "Hurricane Katrina--One Hospital's Experience." Critical Care (London, England) 10(1):109.

Balicer RD, SB Omer, DJ Barnett, and GS Everly Jr. 2006. "Local Public Health Workers' Perceptions Toward Responding to an Influenza Pandemic." BMC Public Health 6:99.

Bayer R. 1988. "AIDS and the Duty to Treat: Risk, Responsibility, and Health Care Workers." Bulletin of the New York Academy of Medicine 64(6):498-505.

Berggren R. 2005. "Hurricane Katrina. Unexpected Necessities--Inside Charity Hospital." The New England Journal of Medicine 353(15):1550-1553.

Bluth EI, D Kay, D Smetherman, D DeVun, J Eick, C Matthews, and M Sullivan. 2007. "Managing in a Catastrophe: Radiology during Hurricane Katrina." AJR.American Journal of Roentgenology 188(3):630-632.

Braun, B. I., N. V. Wineman, N. L. Finn, J. A. Barbera, S. P. Schmaltz, and J. M. Loeb. 2006. Integrating hospitals into community emergency preparedness planning. Annals of Internal Medicine 144, (11) (Jun 6): 799-811.

Campbell A. 2004. The SARS Commission Interim Report: SARS and Public Health in Ontario. The Commission to Investigate the Introduction and Spread of SARS in Ontario, Toronto, Ontario. 
Campbell A. 2005. The SARS Commission Second Interim Report: SARS and Public Health Legislation. The Commission to Investigate the Introduction and Spread of SARS in Ontario, Toronto, Ontario.

Campbell A. 2006. The SARS Commission Final Report: Spring of Fear (Vol. 1-3). The Commission to Investigate the Introduction and Spread of SARS in Ontario, Toronto, Ontario.

Carter D, J Lantos, and J Hughes. 1996. "Reassessing Medical Students' Willingness to Treat HIVInfected Patients." Academic Medicine : Journal of the Association of American Medical Colleges 71(11):1250-1252.

Chen NH, PC Wang, MJ Hsieh, CC Huang, KC Kao, YH Chen, and YH Tsai. 2007. "Impact of Severe Acute Respiratory Syndrome Care on the General Health Status of Healthcare Workers in Taiwan." Infection Control and Hospital Epidemiology: The Official Journal of the Society of Hospital Epidemiologists of America 28(1):75-79.

Chua SE, V Cheung, C Cheung, GM McAlonan, JW Wong, EP Cheung, MT Chan, MM Wong, SW Tang, KM Chouy, MK Wong, CM Chu, and KW Tsang. 2004. "Psychological Effects of the SARS Outbreak in Hong Kong on High-Risk Health Care Workers." Canadian Journal of Psychiatry.Revue Canadienne De Psychiatrie 49(6):391-393.

Cohen J. 1992. "Access to Medical Care for HIV-Infected Individuals under the Americans with Disabilities Act: A Duty to Treat." American Journal of Law \& Medicine 18(3):233-250.

DePalma A. June 25, 2007. "Ex-EPA Chief Defends Role in 9/11 Response.” The New York Times.

Douglas CJ, CM Kalman, and TP Kalman. 1985. "Homophobia among Physicians and Nurses: An Empirical Study." Hospital \& Community Psychiatry 36(12):1309-1311.

Dwyer J and DF Tsai, 2008. "Developing the Duty to Treat: HIV, SARS, and the Next Epidemic." Journal of Medical Ethics 34(1): 7-10.

Ehrenstein BP, F Hanses, and B Salzberger. 2006. "Influenza Pandemic and Professional Duty: Family or Patients First? A Survey of Hospital Employees." BMC Public Health 6:311.

Feeney, J. M., R. Goldberg, J. A. Blumenthal, and M. K. Wallack. 2005. September 11, 2001, revisited: A review of the data. Archives of Surgery (Chicago, Ill.: 1960) 140, (11) (Nov): 1068-73.

Gerbert B, BT Maguire, T Bleecker, TJ Coates, and SJ McPhee. 1991. "Primary Care Physicians and AIDS. Attitudinal and Structural Barriers to Care." JAMA: The Journal of the American Medical Association 266(20):2837-2842.

Grace SL, K Hershenfield, E Robertson, and DE Stewart. 2005. "The Occupational and Psychosocial Impact of SARS on Academic Physicians in Three Affected Hospitals." Psychosomatics 46(5):385391.

Hall LM, J Angus, E Peter, L O'Brien-Pallas, F Wynn, and G Donner. 2003. "Media Portrayal of Nurses' Perspectives and Concerns in the SARS Crisis in Toronto." Journal of Nursing Scholarship: An Official Publication of Sigma Theta Tau International Honor Society of Nursing / Sigma Theta Tau 35(3): 211-216. 
Hanfling, D, et. al. 2005. "Will They Come to Work? Evaluating Healthcare Workforce Knowledge and Intent Regarding Hospital Disaster Response." Presented at the Mid-Atlantic Society for Academic Emergency Medicine Regional Research Meeting, Washington D.C., September 23, 2005.

Harden B. February 18, 2001. “Dr. Matthew's Passion.” The New York Times.

Huber SJ and MK Wynia. 2004. "When Pestilence Prevails...Physician Responsibilities in Epidemics." The American Journal of Bioethics 4(1):W5-11.

Joint Commission on Accreditation of Healthcare Organizations (JCAHO). 2003. Healthcare at the Crossroads: Strategies for Creating and Sustaining Community-Wide Emergency Preparedness Systems. Joint Commission on Accreditation of Healthcare Organizations, Oakbrook Terrace, Illinois.

Koh D, MK Lim, SE Chia, SM Ko, F Qian, V Ng, BH Tan, KS Wong, WM Chew, HK Tang, W Ng, Z Muttakin, S Emmanuel, NP Fong, G Koh, CT Kwa, KB Tan, and C Fones. 2005. "Risk Perception and Impact of Severe Acute Respiratory Syndrome (SARS) on Work and Personal Lives of Healthcare Workers in Singapore: What can we Learn?" Medical Care 43(7):676-682.

Lancee WJ, RG Maunder, DS Goldbloom, and Coauthors for the Impact of SARS Study. 2008. "Prevalence of Psychiatric Disorders among Toronto Hospital Workers One to Two Years after the SARS Outbreak." Psychiatric Services (Washington, D.C.) 59(1):91-95.

Link RN, AR Feingold, MH Charap, K. Freeman, and SP Shelov. 1988. "Concerns of Medical and Pediatric House Officers about Acquiring AIDS from their Patients." American Journal of Public Health 78(4):455-459.

Lundgren RE and AH McMakin. 2004. Risk Communication : A Handbook for Communicating Environmental, Safety and Health Risks, 3rd ed. Battelle Press, Columbus, Ohio.

Masterson L, C Steffen, M Brin, MF Kordick, and S Christos. 2008. "Willingness to Respond: Of Emergency Department Personnel and their Predicted Participation in Mass Casualty Terrorist Events." The Journal of Emergency Medicine , May 29, 2008.

Maunder R. 2004. "The Experience of the 2003 SARS Outbreak as a Traumatic Stress among Frontline Healthcare Workers in Toronto: Lessons Learned." Philosophical Transactions of the Royal Society of London.Series B, Biological Sciences 359(1447):1117-1125.

Maunder R, J Hunter, L Vincent, J Bennett, N Peladeau, M Leszcz, J Sadavoy, LM Verhaeghe, R Steinberg, and T Mazzulli. 2003. "The Immediate Psychological and Occupational Impact of the 2003 SARS Outbreak in a Teaching Hospital." CMAJ : Canadian Medical Association Journal = Journal De l'Association Medicale Canadienne 168(10):1245-1251.

McAlonan GM, AM Lee, V Cheung, C Cheung, KW Tsang, PC Sham, SE Chua, and JG Wong. 2007. "Immediate and Sustained Psychological Impact of an Emerging Infectious Disease Outbreak on Health Care Workers." Canadian Journal of Psychiatry.Revue Canadienne De Psychiatrie 52(4):241247.

Okie S. 2008. "Dr. Pou and the Hurricane--Implications for Patient Care during Disasters." The New England Journal of Medicine 358(1):1-5. 
Qureshi KA, RR Gershon, JA Merrill, A Calero-Breckheimer, M Murrman, KM Gebbie, LC Moskin, L May, SS Morse, and M Sherman. 2004. "Effectiveness of an Emergency Preparedness Training Program for Public Health Nurses in New York City." Family \& Community Health 27(3):242-249.

Qureshi K, RR Gershon, MF Sherman, T Straub, E Gebbie, M McCollum, MJ Erwin, and SS Morse. 2005. "Health Care Workers' Ability and Willingness to Report to Duty during Catastrophic Disasters." Journal of Urban Health : Bulletin of the New York Academy of Medicine 82(3):378-388.

Ramalingaswami V. 2001. "Psychosocial Effects of the 1994 Plague Outbreak in Surat, India." Military Medicine 166(12, Suppl): 29-30.

Rambaldini G, K Wilson, D Rath, Y Lin, WL Gold, MK Kapral, and SE Straus. 2005. "The Impact of Severe Acute Respiratory Syndrome on Medical House Staff: A Qualitative Study." Journal of General Internal Medicine: Official Journal of the Society for Research and Education in Primary Care Internal Medicine 20(5):381-385.

Reynolds B, W Hall, ML Vanderford, and U.S. Centers for Disease Control and Prevention. 2002. Crisis + Emergency Risk Communication: By Leaders for Leaders. Centers for Disease Control and Prevention, Atlanta, Georgia.

Reynolds G. April 18, 2004. "Why Were Doctors Afraid to Treat Rebecca McLester?" The New York Times.

Singer PA, SR Benatar, M Bernstein, AS Daar, BM Dickens, SK MacRae, RE Upshur, L Wright, and RZ Shaul. 2003. "Ethics and SARS: Lessons from Toronto." BMJ (Clinical Research Ed.) 327, (7427) (Dec 6): 1342-4.

Styra R, L Hawryluck, S Robinson, S Kasapinovic, C Fones, and WL Gold. 2008. "Impact on Health Care Workers Employed in High-Risk Areas during the Toronto SARS Outbreak." Journal of Psychosomatic Research 64(2):177-183.

U.S. Centers for Disease Control and Prevention. 2007. Hospital Pandemic Influenza Planning Checklist. U.S. Centers for Disease Control and Prevention, Atlanta, Georgia. Accessed 7/24/2008 at http://www.pandemicflu.gov/plan/healthcare/hospitalchecklist.html.

Vawter DE, KG Gervais, JE Garrett, and Pandemic Influenza Ethics Work Group. 2007. "Allocating Pandemic Influenza Vaccines in Minnesota: Recommendations of the Pandemic Influenza Ethics Work Group." Vaccine 25(35):6522-6536.

Zuger A, and SH Miles. 1987. "Physicians, AIDS, and Occupational Risk. Historic Traditions and Ethical Obligations." JAMA: The Journal of the American Medical Association 258(14):1924-1928. 
Appendix A

List of Interviewees

A. 1 



\section{Appendix A: List of Interviewees}

Ken Back

Emergency Preparedness Director

Washington State Department of Health

Rick Buell

Regional Emergency Coordinator-Region X

Department of Health and Human Services

Dr. Allan Detsky

Physician in Chief

Mt. Sinai Hospital, Toronto, Canada.

Cynthia Dold

King County Healthcare Coalition Program Manager

Public Health - Seattle \& King County

Dr. Jeff Duchin,

Chief, Communicable Disease Control

Public Health - Seattle \& King County

John Erickson

Emergency Preparedness Director

Washington State Department of Health

Dr. Dan Hanfling

Director, Emergency Management and Disaster Medicine

Inova Health System

Clinical Professor, Department of Emergency Medicine

George Washington University

Dr. Maxine Hayes

State Health Officer

Washington State Department of Health

Dr. Bonnie Henry

Director, Public Health Emergency Management

British Columbia Centre for Disease Control

Dr. Jack Hermann

Senior Advisor, Public Health Preparedness

National Association of County \& City Health Officials (NACCHO)

Marianne Klaas

Director, Accreditation and Safety

Swedish Medical Center, Seattle, Washington

Marty Lafave

Commander, Emergency Medical Services 
Bellevue Fire Department, Bellevue, Washington

Michael Loehr

Preparedness Director

Public Health - Seattle \& King County

Dr. John D. Malone

Professor of Medicine (Infectious Disease)

Uniformed Services University of the Health Sciences, Bethesda, Maryland

Dr. Greg Martin

Navy Infectious Diseases Specialty Leader

Uniformed Services University of the Health Sciences, Bethesda, Maryland

Michelle McDaniel

Behavioral Health Planning Manager

Public Health - Seattle \& King County

Dr. Peter Moyer

Medical Director

Boston Emergency Medical Services, Fire, and Police

Anne Newcombe

Clinical Nurse Manager, Emergency Services

Harborview Medical Center, Seattle, Washington

Dr. Carol North

Professor of Psychiatry and Surgery/Emergency Medicine

Psychiatric Epidemiolosist

Veterans' Affairs North Texas Health Care System, Dallas, Texas

University of Texas Southwestern Medical Center

Dr. Lewis Rubinson

Assistant Professor

Division of Pulmonary and Critical Care Medicine

University of Washington, Harborview Medical Center

Alison Schletzbaum

Regional Medical Resource Center

Seattle King County Healthcare Coalition

Commander Eric Sergienko, M.D.

Medical Corps

United States Navy

Peggi Shapiro

Director, Disaster Readiness

Washington State Hospital Association

Andrew Stevermer

Regional Emergency Coordinator-Region X 
Department of Health and Human Services

A.D. Vickery

Assistant Chief, Risk Management

Seattle Fire Department

Ron Weigelt

Human Resources Service Delivery Manager

Public Health - Seattle \& King County

Chris Williams

Emergency Preparedness Director

Washington State Department of Health 

Appendix B

Interview Protocol 



\title{
Appendix B: Interview Protocol
}

\section{Healthcare Worker Behavior during a Naturally-Occurring Epidemic or an Act of Biological Terrorism: Past Examples and Future Considerations}

\author{
Interview Protocol
}

Please Return To:

Jay Miller

Pacific Northwest Center for Global Security

1100 Dexter Ave North, Suite 400

Seattle WA 98109

Fax: 206-528-3552

James.Miller@pnl.gov

Name:

Title:

Affiliation/Organization:

Address:

Tel. Email:

Date of contact:

Purpose [Check one]: _ MD _ RN _ EMS _ Local/County _ State _ Federal _ First-hand

\section{Organization Type:[Check one]}

Hospital_Government-Federal

Government-Local Other

Government-State

Other NGO (non-hospital)

Introduction/Purpose: The purpose of this interview is to:

- Understand how healthcare workers (HCWs) might respond in a biological event

- Determine the material and psychosocial resources that will encourage attendance by HCWs during the response to a biological event

- Examine the policies and mechanisms in place to encourage attendance or deal with absenteeism among HCWs during a biological event

- Explore whether additional policies or actions are necessary to minimize absenteeism and provide a favorable work atmosphere for HCWs during a disaster 
- Serve as a conduit between local agencies and state/federal agencies; i.e., communicate needs of the people on the ground to the policy makers.

I will not attribute or quote anything directly to you — we are just trying to get a sense of what you, and other people working in similar capacities, are thinking.

There may be questions that are not applicable to you. During this project, we are interviewing a range of people from different institutions, and consequently not all the questions are relevant to every interviewee. Feel free to skip any question that you think is not relevant.

\section{Questions:}

1. Does your organization have a policy on the duty/responsibility of HCWs to provide care even if it puts them in danger

2. Do you feel that HCWs can be reasonably justified in not wanting to risk their safety by caring for patients with a disease such as SARS, or a patient who has been exposed to radiological material? Are there specific situations in which you would support an employee who wished to be absent from work (for instance, if a husband and wife were both HCWs?) Or do healthcare workers always have a "duty to treat?"

3. During past emergencies, have there been problems with absenteeism?

a. If so, what do you perceive to be the causes of absenteeism?

b. Did your organization take any steps to make it easier for employees to attend work?

c. Did your organization take any action against employees who missed work?

d. Did the event require long-term efforts on the part of the organization to care for the mental and emotional needs of employees?

4. Did the absent employees eventually return to work? If so, did they return during the response to the disaster, or after the response had been completed?

5. Did some employees never return to work after the disaster?

6. What would be a significant or problematic rate of absenteeism? In other words, at what level would care [or operations] start to be affected?

7. Would you expect a significant rate of staff absenteeism during a biological event?

8. Would you expect that staff would react differently during a biological event versus a radiological or nuclear event? 
9. Does your organization currently have plans or policies to curb absenteeism during a major disaster?

10. Does your organization have plans to assist with barriers that HCWs may face during a biological or nuclear event? Survey data have indicated that transportation problems, personal health issues, childcare, eldercare, and pet care obligations are perceived as barriers to attending work.

11. How would your organization address the psychosocial needs of HCWs during a biological or nuclear event? Survey data have indicated that fear of infection, and often more significantly, fear of infecting family members or loved ones, limit the willingness of HCWs to report to work.

12. How would your organization deal with the long-term mental and emotional effects on HCWs caused by a major disaster

13. Who in the organization would be responsible for implementing these measures? Who would staff perceive as the leader of the response to the disaster?

14. What would the communication strategy be in communicating with HCWs? Who would be doing the communication?

15. At your institution, do you feel that the overall morale of the staff would have an impact on the level of absenteeism or on the ability of the institution to respond to a disaster? What do you perceive to be the general level of morale at your institution?

16. Would employees receive overtime pay if they had to work longer hours to respond to a major biological event?

17. Would your organization offer supplemental insurance to employees during a biological event that posed significant risk to their safety? Alternatively, do you feel that the government should provide such insurance?

18. Is there any tool that DHS or another agency could provide that would assist you in managing your staff during a biological event? (A tool that simulates or models the impacts of absenteeism, a handbook on risk communication with healthcare workers, etc.)

19. Are there other elements of HCW behavior in a biological event that you feel would need to be addressed?

20. Would it be alright for me to put your name in list of interviews appended to the report, or would you prefer for this to be completely anonymous?

21. Would you like a copy of my report when I finish it?

\# Name

Organization

Address

City, State and ZIP Code
\# Organization

Address

City, State and ZIP Code 


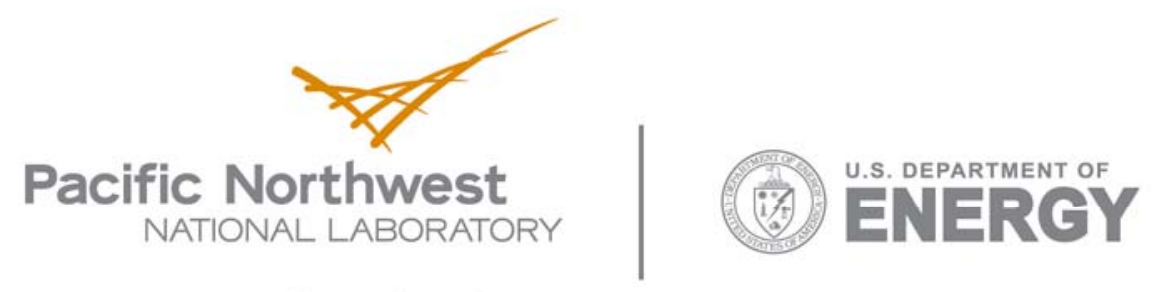

902 Battelle Boulevard

P.O. Box 999

Richland, WA 99352

1-888-375-PNNL (7665)

www.pnl.gov 